\title{
Alliance Catering at Deakin: the Economics of University Cafeterias
}

Theresa Irene Patilaya, Thi Thuy An Pham, My Nguyen Nguyen, Zhen Wu \& Yu Zhu

\section{Introduction}

University cafeterias are a common and crucial component of university life as they provide cheap and convenient meals for students. Ideally, university cafeterias should also be responsible for providing nutritious food at reasonable prices. In practice though, university cafeterias often provide less nutritious food and at high prices.

One reason for why this may happen is that cafeterias are aware of their unique market power. For instance, students consider the opportunity and transportation costs in the price they are willing to pay for on-campus services. The costs of preparing meals at home or walking to the alternatives are high, as students may prefer to use the time for studying or socializing. Thus, for a variety of reasons, university cafeterias become more practical in their delivery of services by placing less concern on the health quality of products and the fairness of prices.

In this paper, we study the market power of university cafeterias specifically due to a locational advantage by analyzing the case of the Alliance Cafeteria operating in Buildings La and Lb at Deakin University's Burwood campus in Melbourne. We begin by examining Alliance as a monopolistically competitive firm and assess how its location gives market power. 


\section{Alliance's Market at Deakin}

The Alliance cafeteria operates in what can be understood as a monopolistically competitive market at Deakin University. There are usually three characteristics of monopolistic competition: a large number of firms, differentiated products and free entry and exit. At Deakin there are seven on-campus cafeterias providing a range of slightly differentiated fast foods and serving a small number of customers. During our interview with Alliance's supervisor we learned that this differentiation in the products also accommodates the preferences of Deakin's international student community. Finally, there are no barriers to open cafeterias at Deakin, as long as premises are available. Firms only need to sign a five-year-contract and qualify on the basis of some general conditions applicable to the food service industry in Australia.

Firms operating in a monopolistically competitive market are able to charge different prices from their rivals because they have customers with a certain degree of inelastic demand. This is affirmed by comparing Alliance's prices with its rivals for similar items as table 1 illustrates.

Table 1 below shows that Alliance charges higher prices than others for the same products. A key reason for this is that both Café Plateau and Coles are located further away from Buildings $\mathrm{La}$ and $\mathrm{Lb}$ where Alliance itself is located. This suggests that a key reason for the market power that Alliance enjoys is due to its more secluded location from its rivals; therefore, we now turn to examining how location provides a monopolistically firm with market power. 
Table 1: A price comparison between Alliance, Cafe's Plateau and Coles

\begin{tabular}{c|c|c|c}
\hline & Alliance & Café Plateau & Coles \\
\hline Donuts & 2.5 & 2.2 & 0.7 \\
\hline Chocolate Bar & 2.4 & 2.2 & 2.0 \\
\hline Fruit Bread & 2.5 & - & - \\
\hline Coffee & 2.7 & 2.6 & 0.9 \\
\hline Chips & 2.5 & - & 1.75 \\
\hline $\begin{array}{c}\text { Franklin } \\
\text { Water }\end{array}$ & 2.5 & 2.2 & 2.8 \\
\hline $\begin{array}{c}\text { Soft Drink } \\
\text { (600ml) }\end{array}$ & 3.2 & 3.0 & 2.9 \\
\hline $\begin{array}{c}\text { Red bull } \\
\text { Ham, Cheese } \\
\text { \& Tomato }\end{array}$ & 3.3 & 3.0 & - \\
\hline $\begin{array}{c}\text { Plain } \\
\text { Croissants }\end{array}$ & 3.8 & - & \\
\hline
\end{tabular}

Patilaya et. al. 


\section{Location Models}

Hotelling's Model

Hotelling's Model (1929, cited in Carlton and Perloff, 2005) is a monopolistic competition model explaining the location and pricing behaviour of firms. If there were two firms with identical products and prices, consumers simply purchase from the nearest store. So consider that the geographic space of Deakin is bounded between two extreme points on a line - Building $\mathrm{Lb}$ at one end and Building $\mathrm{He}$ at the other. Now suppose we have two firms, Alliance and Plateau Café. The Hotelling's Model suggests that both firms would move their locations until they reached an equilirium location where the transportation cost incurred by consumers is equal for both firms and both firms maximize their respective profits. This happens to be at the centre of the geographic space as shown by point e on figure 1 .

Figure 1: A Hotelling's Model Illustration for the location of Deakin's Cafeterias

$$
\text { Equilirium }
$$

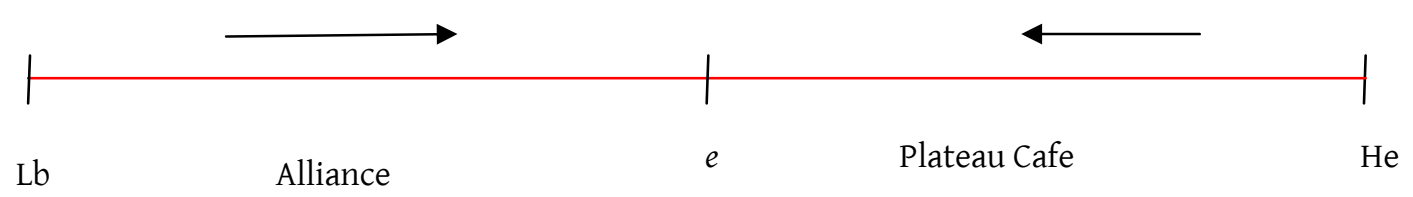

However, this model is not applicable in Alliance's case since the locations of cafeterias are fixed and no further locations are available. Further, Deakin's cafeterias sell differentiated products instead of identical ones. Thus, we extend our analysis by considering Salop's Circle Model.

\section{Salop's Circle Model}

An application of Salop's Circle Model for our case would illustrate the cafeterias at Deakin as being located around a circle instead of along a line like in Hotelling's Model. Some cafes would be closer to each other while others would be located further apart 
along the perimeter of the circle. Further, to particularise the analysis to Alliance's case, we could divide consumers into two groups. The first group is comprised of those whose main activities are centred in Buildings La and Lb. The second group are those whose activities are not concentrated in Buildings La and Lb.

To understand the utility of consumers in both groups, consider the following equation

$$
\mathrm{U}_{\left(\mathrm{t}, \mathrm{t}^{*}\right)}=\mathrm{u}-\mathrm{c}\left|\mathrm{t}-\mathrm{t}^{*}\right|
$$

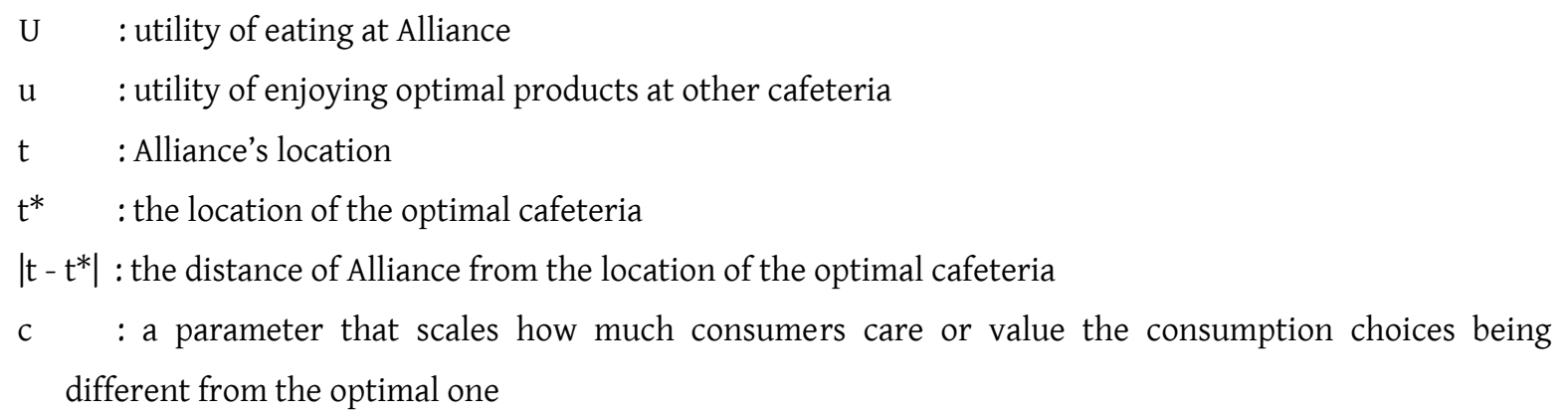

The equation suggests that that utility is less likely to be maximized for students located in Buildings $\mathrm{La}$ and $\mathrm{Lb}$ when the ideal cafeteria is located at a greater distance from Alliance. Therefore, for the first group, when students do not care intensely about a more optimal choice (i.e. $\mathrm{c}$ is not very high) due to greater distances, the utility of eating at Alliance ' $U$ ' will remain relatively higher. This happens as consumers consider the opportunity and transportation costs. So, for example, if a given student values socializing with peers but her peers have lower perceived utilities from travelling to the outlet she considers to be a more optimal choice, this would indirectly lower the level of $\mathrm{c}$ for her as well. 
For the second group of students the analysis is reversed if Alliance is an optimal choice for them and would obviously not matter to those for whom Alliance is perceived as an inferior choice relative to the other options that are closer to them.

Since Alliance is located further from other cafeterias such as Café Plateau, for a certain set of consumers it can behave as a monopolistic firm. Therefore, Alliance can charge high prices or serve less nutritious food since the utility loss from buying these high priced products is less than buying the cheaper or more nutritious products at other cafeterias. In other words, the higher price is still lower when the costs incurred in eating at the other cafeterias are considered.

Further, using Salop's Circle Model we could consider the outside or off campus options available to Deakin students by considering the following condition

$$
\operatorname{Max}_{\text {Alliance }}\left[\mathrm{U}_{\left(\mathrm{t}, \mathrm{t}^{*}\right)}-\mathrm{p}\right] \geq \mathrm{u}
$$

where $\mathrm{u}$ stands for the surplus from the outside good and $\mathrm{p}$ stands for the prices of products sold by Alliance. This equation shows that students will only buy Alliance's products as long as the surplus from consumption at Alliance is the same or exceeds the surplus from off campus options. In Alliance' case, the outside options could be Hungry Jack's which is located at a comparable distance from Alliance as other on-campus cafeterias. Hungry Jack's even offers a special discount to attract students.

However, not many students go to Hungry Jack's, as going there still incurs higher costs. Therefore, as long as the utility from eating at Alliance is equal to or higher than the utility from the outside option, consumers will still buy Alliance's products.

$$
\operatorname{Max}_{\text {Alliance }}\left[v-c\left|t-t^{*}\right|-p\right]>0
$$

This suggests the question about what would be the reservation price for students in the first group, or the highest price these students would be willing to pay or the highest price 
Alliance could charge. Salop's Circle Model provides an insight into this question in equation (3) where $\mathrm{v}$ is the reservation price. It reasonably suggests that students will shop at Alliance only if the surplus is positive.

Equation (3) also explains why Alliance's demand must be elastic, a fact that verified in a survey we conducted on 100 students revealing that $19 \%$ of students would choose the alternatives if Alliance were to increase its prices by $10 \%$. This elastic demand also explains the reasons of why Alliance is more monopolistically competitive than purely monopolistic.

\section{Alliance's Monopoly and Competitive Regions}

The monopoly region, or the area within which Alliance can operate as a local monopoly (Figure 2) is applicable for students whose activities are in La and Lb buildings and for whom the values for $\mathrm{c}$ are low and $\mathrm{v}$ are high. The competitive region (Figure 3) is applicable for the second group of students, whose activities are not centred in $\mathrm{La}$ and $\mathrm{Lb}$ buildings and Alliance is not considered to be an optimal choice.

Figure 2: Monopoly Region for Alliance

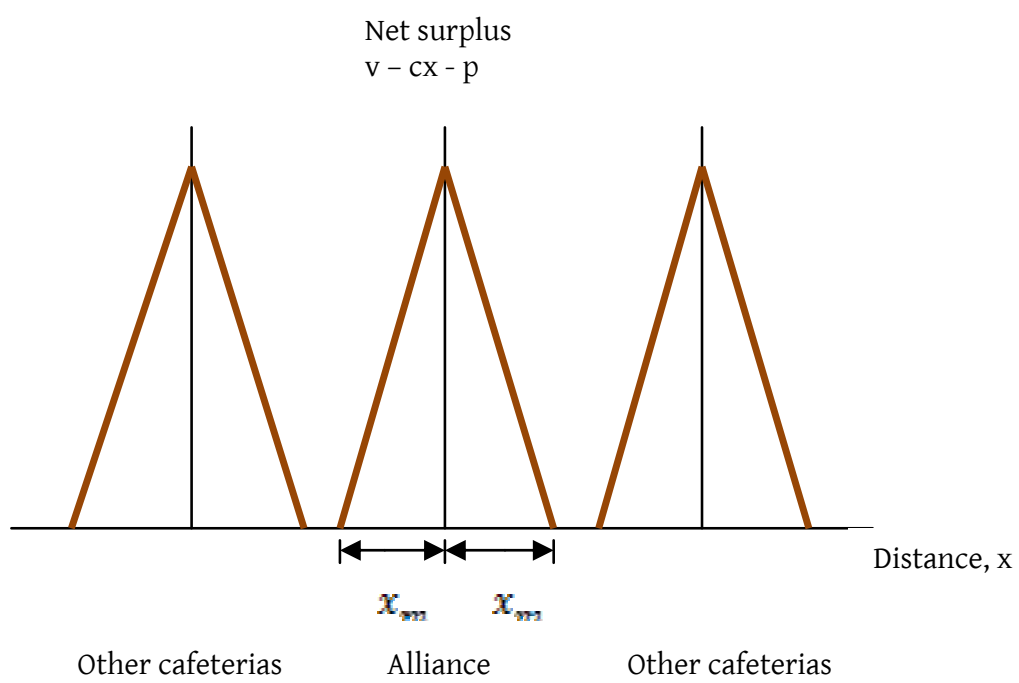

Patilaya et. al. 
Figure 3: Competitive Region for Alliance

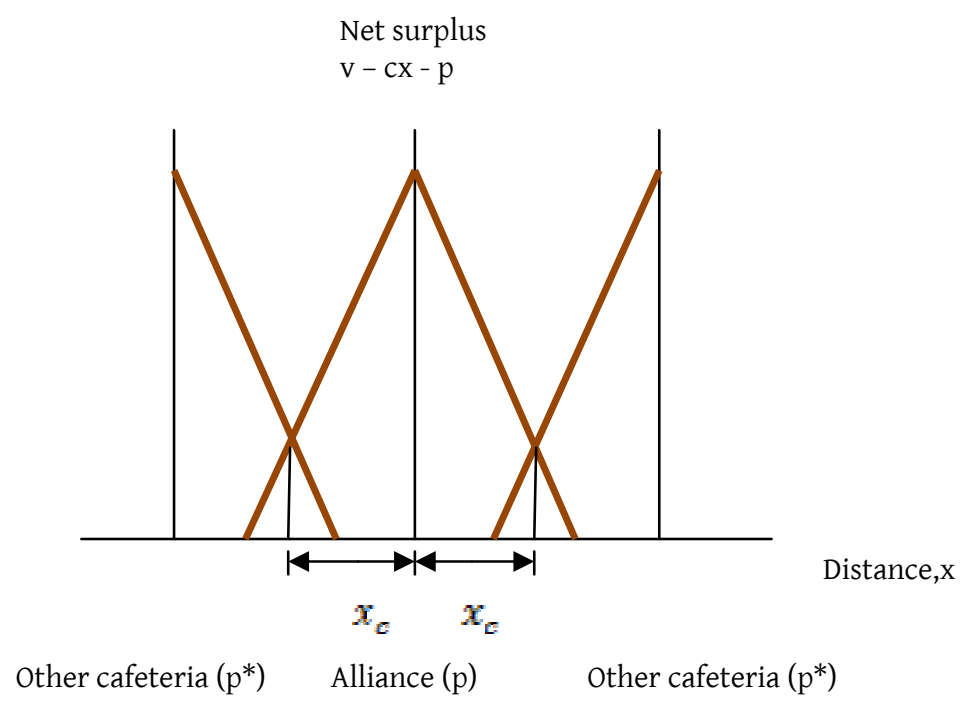

The differences between these two regions are in terms of the range of students they capture and the quantity demanded. Alliance's monopoly region captures the students within the following distance:

$$
x_{m L}=\frac{v-p}{\Theta}
$$

Figure 2 shows that the further the other cafeterias' locations are from Alliance, the lower the consumer' surplus would be for Alliance's customers. Alliance would capture consumers in ' $2 x_{m}$ ' circle distance. Thus, if there are 'L' students located uniformly near Alliance, the quantity demanded is ' $\mathrm{Q}_{\mathrm{m}}=2 x_{m} \mathrm{~L}$ ' or: 


$$
\mathrm{Q}_{\mathrm{m}}=\frac{2 L}{6}(\mathrm{v}-\mathrm{p})
$$

which suggests, as we should expect, that the quantity demanded demands inversely on how much students care about the quality of Alliance's products, both in terms of the reservation price as well as how they perceive the location of other, more optimal, options compared to Alliance.

Alliance also faces a competitive region for students that are located between two or more cafeterias (for instance, those students who have classes in buildings that are all over the campus and not just in Buildings $\mathrm{La}$ and $\mathrm{Lb}$ ) and may purchase products from the cafeteria that gives the highest surplus. Hence, Alliance may lose such customers to other rivals.

Suppose that the two nearest cafeterias are located ' $1 / \mathrm{n}$ ' distance from Alliance and charge ' $p$ ". Thus, Alliance gets the consumers within the ' $x_{n}$ ' distance where consumers get the same satisfaction from Alliance as from the other cafeterias:

$$
\mathrm{v}-\mathrm{c} x_{c}-\mathrm{p}=\mathrm{v}-\mathrm{c}\left(\frac{1}{n}-x_{c}\right)-\mathrm{p}^{*}
$$

The areas where the distance from customers to Alliance and to other cafeterias is equal in Figure 3 make the consumers to be indifferent to purchase Alliance's products or other cafeterias'. Therefore, the quantity demanded for competitive region is:

$$
\mathrm{Q}_{c}=\frac{L}{n}\left(\frac{c}{n}+\mathrm{p}^{*}-\mathrm{p}\right)
$$




\section{Market Externalities and Deakin's role}

There are two types of externalities imposed by the activities of the Alliance Cafeteria in Buildings La and $\mathrm{Lb}$ at Deakin. The positive externalities are that Alliance provides some ancillary services for students such as free use of its microwaves and a place to gather centrally and socialize. However, these positive externalities cannot offset the negative externalities. For instance, Alliance charges high prices to students as we observed through our investigations of prices at other places. Moreover, and this is the key problem in our minds, Alliance tends to sell fast food with little nutrition, as it can be stored longer and sold faster such as candies and deep-fried foods. Even when Alliance does provide healthy food options such as salad or fruits, it charges its customers high prices. Consequently, students end up choosing relatively cheaper products (such as the fast food) instead. This implies that as Alliance engages in maximizing its profits, the social marginal costs it imposes on Deakin's students become higher than the social marginal benefits.

Interestingly, Deakin seems to have an insignificant role or ability in overcoming these market failures. For instance, the numbers of vending machines, and the alternatives to Alliance in Buildings $\mathrm{La}$ and $\mathrm{Lb}$ are limited.

We suggest that to overcome this problem Deakin should consider involving student organizations in monitoring the service of on-campus cafeterias. Greater surplus for students and higher social marginal benefits could be achieved if Deakin were to consider this information in making its decisions on contracts for on-campus cafeteria services.

\section{References}

- Carlton, DW and Perloff, JM (2005) Modern Industrial Organization, 4th, Pearson Addison Wesley, New York.

- Interview with Alliance's supervisor, 2 April, 2010.

- Taggart, DM; Findlay, C and Parkin, M (2003), Microeconomics, $4^{\text {th }}$ edition, Pearson Education, New South Wales. 